MA MAJOR RESEARCH PAPER

\title{
State Control of the Internet in China
}

Hua Wang

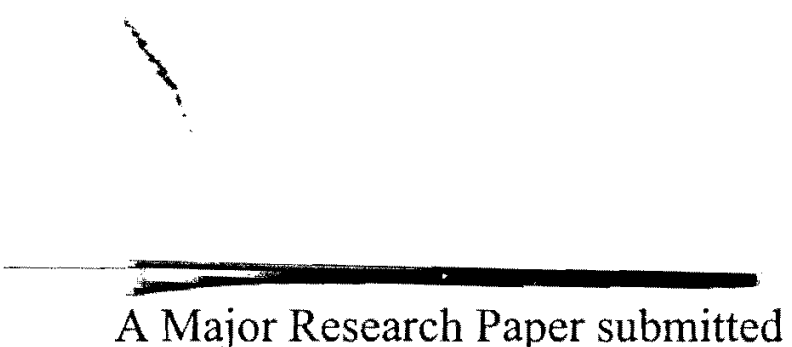

in partial fulfillment of the requirements for the degree of Master of Arts

Joint Graduate Program in Communication \& Culture

Ryerson University - York University

Toronto, Ontario, Canada

April 22, 2003 


\section{Introduction}

The Internet is a "network of networks"; it is a system of computers set up around the world speaking to each other through telephone and cable lines. It is a product of technology and was born of a need to develop a reliable communication network to withstand a nuclear attack in U.S. in the 1970s. After its birth, its unanticipated life as medium in the cultural industries has grown quickly. Once it began to take its role on the historical stage, it expanded rapidly worldwide. According to the Internet Software Consortium, by 1981 , there were only 213 host computers connected to the Internet worldwide, - but at the end of 2002 the number has increased to $147,344,723$ (Internet Software Consortium, 2002). The immense quantity of information available on the Internet and the ease of communication which it offers, attracts more and more people to sign up with an operator who can provide a gateway to this new medium. As a result, today, 'Internet' has become a household word, and several million new users a month make the necessary arrangements to become connected.

On the nation level, every country is promoting the development of the Internet because it is generally viewed as a prime tool for obtaining national wealth and power in the information age. Numerous countries have tied their economic development programs to the Internet because of its on-line availability of a huge range of data. But besides useful information, there are also many undesirable contents on the Internet. So, for various reasons, a number of countries attempt to control the information on the Internet and some have already issued regulations, including the United States, Canada, Germany, China, Vietnam, Singapore, Britain, France, Holland, Belgium, Australia, Kenya and etc. 
The Internet landed in China in 1987, only 9 years after the "Open-Door Policy" in 1978. Although the history of the Internet in China is not long, the speed of the Internet's development has been rapid. According to the statistics of China National Network Information Center (CNNIC), the number of Chinese Internet users already reached 33.7 million at the end of 2001 , and this number quickly increased to 45.8 million by the end of June of 2002 . The Chinese government also recognized the huge potential brought by the Internet to the economic growth in the country and started to launch several projects to enhance its development in 1990s.

But, for regimes of democratic centralism, like China, the Internet is a doubleedged sword. Dramatically distinguished from other traditional mediums, the Internet enhances a much freer information flow and implies libertarianism and anarchism in the virtual world, which collides with the Chinese government's conventional practice of media control. Although the Internet is not as easy to control as other traditional mediums, the Chinese government is intent on maintaining control and censorship on it.

As the only existing major communist country, China takes media as the government's opinion organ. It stretches its control to every form of media, including newspapers, film, TV, and advertisements. Much existing literature on the politics and media uses China as a typical example of strict media control.

This study poses the following research questions: What is the present situation of the Internet in China? How does the Chinese government control the Internet? What are the methods of controlling the Internet?

In this study, secondary sources are employed as the main reference resource, such as data from books, journals as well as information taken from websites. The 
collected data focus on existing government policy and practical methods of control to illustrate these three research questions in detail in order to provide a clear picture of the application and control of the Internet in present day in China.

However, because of the unique technological characteristics of the Internet, it is not easy to control its information flows. Tsui points out that "from a technical point of view, the Internet is a packet-switched network, meaning it is designed so that data are sent around in small packets and are able to take another route if one part of the network is down (Tsui, 2001). So, although for various reassons, a number of countries control the undesired content on the Internet, none of them have fully succeeded. This is also the case with China.

This research paper will start with the description of the Internet application in China to illustrate the rapid development of this new medium in this ancient Eastern country. It will trace the Internet's development path in China and will quote the facts and figures from CNNIC to demonstrate the rapid growth of the Internet. Then, the national policy of the Internet administration and related regulations will be analyzed to discuss the governmental attitudes towards, and future direction of Internet development. Following that, the actual methods of the Internet control will be provided to illustrate how the Chinese government regulates information flows on the Internet in practice. Finally, I will attempt to address what features of the Internet make it difficult for states and governments to control its operation. 


\section{Chapter One: Overview of the Internet Worldwide and its Current Status in China}

\subsection{The Internet Worldwide}

Today it is common to hear the Internet described as the most important development in human communications since the invention of the printing press by Johannes Gutenberg in 1450 . The Internet appeared as a martial by-product of the U.S. Department of Defense. In the 1950s, the U.S. Department of Defense started research on "a decentralized communications systems" that would allow researchers and government officials to communicate with one another to withstand a nuclear attack. A computer network seemed to be the most logical way to accomplish this, so the military formed the Advanced Projects Research Agency (ARPA) to study how to connect networks. At the time, there was no reliable way to combine local area networks (LANs), which connected computers in a single location, and wide area networks (WANs), which connected computers across wide geographic areas (Foust, 2002). ARPA sought to create a combination of LANs and WANs that would be called an "internetwork"; ARPA engineers later shortened the term to Internet (Foust, 2002; Comer, 1995).

In 1969 , the successful interconnection of four computers in California and Utah brought ARPANET to come into being. The key innovation in the development of ARPANET, according to Foust, was the use of TCP/IP (transmission control protocol / Internet protocol), a method of data transmission in which information is broken into "packets" that are "addressed" to reach a given destination and once the data reaches its destination, the packets are reassembled to recreate the original message (Foust, 2002). TCP/IP allows many different messages to flow through a given network connection at the same time, and also allows for standardization of data transfer among networks. 
During the 1970s, the network of ARPANET grew rapidly and by 1975, there were about 100 computers connected to ARPANET, and the number grew to 1,000 by 1984 (Clemente, 1998; Foust, 2002). In 1983, ARPANET became formally known as the Internet, and the number of computers connected to it continued to grow at a phenomenal rate. According to Internet Software Consortium, by 1981, there were only 213 host computers connected to the Internet worldwide but by year 2002, the number has increased to 147,344,723 (Internet Software Consortium, 2002).

People usually interchangeably use the terms "Internet" and "World Wide Web (WWW)", but they have different meanings. The Internet only builds up an interconnection of computer networks; it is WWW who brings us "an easy way to link from place to place on the Internet and an easier-to-use graphic interface" (Foust, 2002) and the computer language, HTML (hypertext markup language), allows users with little or no computer skills to explore information on the Internet.

In 1990s, the Internet, particularly the World Wide Web (WWW), was rapidly providing people with access to information, products, services and personal contacts that were virtually impossible several years ago (Nash \& Hoffman, 1995; Sager, 1994; Kenway, 1996). According to Jonscher (1999), the first implementation of the Web appeared in 1990, and Jordan (2001) points out that in early 2000, around 250 million people worldwide had access to the Internet. Today 'Internet' is a household word, and several million new users a month make the necessary arrangements to be on it; they sign up with an operator who can provide a gateway to this intriguing new medium. 


\subsection{Current Status of the Internet in China}

Being the biggest developing country in the world, China possesses advanced electronic technologies and the rapid progress of the Internet is tremendous. September 20, 1987, a day on which "Qian Tianbai, Head of China's Academic Network (CANET), successfully sent the first electronic mail titled 'Crossing the Great Wall to Join the World' through the networks of Italian ITAPAC and German DATEXDP from China to Germany" (Xing, 2001), marks the beginning of the use of the Internet in China. Succeeding development of the Internet had been slow in the decade that followed, but the development from 1995 has been obvious:

..... Internet applications also experienced growth dramatically. From October 1997 to December 1998, only fourteen months, " the international gateway capacity of the four major national service providers (CHINANET, CERNET, GBNET, and CSTNET) swiftly upgraded from $25.4 \mathrm{Mbps}$ to $143.25 \mathrm{Mbps}$, domain names grew from 4,000 to 18,400 , WWW sites climbed from 1,500 to 5,300 , and the subscription jumped from 600,000 to 2.1 million. The same stunning growth kept its momentum in 1999 in which total network gateway capacity reached 351 Mbps, domain names expanded to 48,695 , WWW sites rocketed to 15,153 , and Internet subscription climbed to 8.9 million. Between 1998 and 1999, Internet subscription, domain names and WWW sites in China experienced a 100\% growth every six month." However, all the figures are updated quickly. As of June 2000, the China National Network Information Center (CNNIC) survey indicated that, " China' s Internet subscribers reached 16.9 millions, websites expanded to 27,289 in numbers, and the total international gateway capacity rose to 1,234 Mbps". (Xing, 2001)

These figures indicate that the Internet in China is booming. In the past five years, the development has been so dramatic that nowadays more and more people rely on the 
Internet everyday. Not only do people use the Internct to communicate with others frequently, but the Internet has also been integrated gradually into their everyday life.

According to the latest survey report on Internet development in China released by CNNIC, by the end of June of 2002 , China had over 45.8 million Internet users who stay on line for one hour or more everyday, the third largest number in the world, after the United States and Japan.

The survey shows that China has 16.13 million computers connected to the Internet, among which nineteen percent use a leased line, seventy-four percent use dialup connection and the remaining seven percent use other means. According to the report, most Chinese people choose to get online at home, which it attributes to the popularization of home computers, the construction of broadband in communities and the drop of the Internet access charge. The report also indicates that the proportion of people getting online at school has increased from 19.7 percent in January 2001 to 21.8 percent due to the increase of student Internet users.

The survey discloses that China has almost 300,000 websites including 126,146 websites under the domain of "CN". The survey also finds that people under 35 are the main force of the Internet users in China. There are more students and professionals than people of other occupations among the Internet users. However, the users no longer cluster in information technology (IT) industry and institutions of education and research.

In explaining the purpose of Internet access, 47.6 percent people visit the Internet mainly for obtaining information, followed by entertainment and making friends. The survey concludes that obtaining information is still the primary purpose for the Internet access. 
These figures offered by CNNIC illustrate that the Internet is becoming more and more popular in China. The access to the Internet not only provides them an important source of receiving information and entertainment, but also is changing their traditional way of life. People are using the Internet to read news, do shopping and make friends. The Internet is also helping people find jobs in China. About 35 percent of job seekers found employment online. People are getting used to sending emails instead of writing letters to keep in touch and communicate with others.

When the Internet enriches Chinese people's life, it brings them greater freedom, which was unimaginable decades ago when the country suffered under strict controls and isolation. The Internet breaks down the barriers of space and time, which permits them to conduct global, interactive and mass computer-mediated communication as well as to get access to unprecedented amount of information. The Internet brings a cyberspace without boundaries and opens up new possibilities for individuals. However, this does not necessarily mean that people can get access to the Internet without limitations. In fact, control by the government over the mass media, including the Internet, still exists. Conflicts can inevitably appear when the liberating and open characteristics of the Internet come into conflict with the control by the government.

As McQuail says, despite the common features of the media institutions across societies, the media are also by origin, developed practice and convention very much national institutions in their specific contents and are constrained by domestic political and social pressures (McQuail, 1987). The mass media in China is very different from that in the Western countries. Unlike the Western media, the fundamental function of Chinese media is to guide the society and public to follow the Communist Party of China 
(CPC)'s and the Chinese government's direction. Though the role and function of media in the country remains unchanged, Chinese media has experienced transformation from the heavily controlled totalitarian media model in the 1960s and 1970s, to the current less restricted media model.

During the cultural revolution (1966-1976), the function of Chinese media was considered the mouthpiece of the CPC, which served the needs of the CPC and the government instead of those of the public. It followed a one-way communication paradigm, in which the public was treated as the passive receiver of propaganda from the state-owned media. China during this period was regarded as one of the most isolated countries in modern times.

After the introduction of reform and open-door policy initiated in 1978, China embarked on the path of seeking economic integration into the world economy. As it opened its door wider to the outside world, the media in China was given unprecedented freedom. As the whole country moves from the planned-economy to the market-oriented economy, the government has taken a more open attitude toward the flow of information and has relaxed its control over the media by giving media more autonomy. A key change is reflected in its new definition of the role of the media in the country. The leaders of the $\mathrm{CPC}$ and the government have mentioned on several occasions that the media in the country is not only the mouthpiece of the party, but also the voice of the people. As a result the media in the country is called to work as an instrument for the public to voice their views and opinions about their concerns. By working as the linkage between the government and the people, the Chinese media is no longer the previous pure propaganda machine of the party and the government. With the deepening of the reform, the media is 
now given a new role of working as the watchdog of the party and the government, which allows the media greater freedom in criticizing the officials in the Party and the government. This represents a breakthrough in news reporting in the country. A case in point is the popularity of a national TV program called the Focus, and Southern Weekend, a Guangzhou-based newspaper, which are both famous for bold coverage of corruption and the dark side in the society. Although the criticism and negative reporting on leaders in the Party and the government are still not permitted, these developments mark a big step toward further political relaxation and democracy.

With China's integration into the global economy and its entry into the World Trade Organization (WTO), the government has taken measures to reduce or terminate subsidies for most media institutions and pushed them into market competition. However, while obtaining economic autonomy, the media are still under the political control of the government, which is decided by the government's emphasis on political and ideologicalrelated issues. To keep this in mind will help us understand the Chinese government's attitude toward the development of the Internet.

The above-mentioned reform and open-door policy in China now has direct bearing on Chinese government's attitude toward the Internet. Through the practice of reform in the past two decades, China has realized the importance of economic development in enhancing the general strength of the country and improving people's living standard, which can contribute to social stability. The late leader Deng Xiao-ping, who is honored as the "architect of reform" in China, stressed that backwardness will put a country in a passive position and under attack. After having suffered the bitterness of 
isolation and benefited from the reform, the new generation of leaders highlights reform and the significance of modernization in every governmental rcport.

The Chinese government has recognized early the potential of the information industry in economic and social development, which is considered to outweigh its threat to the political control of the Party. And they are convinced that high technology, including the Intcrnet, will make a critical difference to China's future. As a result it takes positive attitudes towards the developing information industry.

In 1993 China launched the Golden Bridge Projects with the objectives of building a national infrastructure to achieve national modernization and economic development as well as stimulating the development of information technology in China.

In March of 1998, China's National People's Congress approved the establishment of the Ministry of Information Industry. Its main task is to administer the national manufacturing of IT products, national communication and software industries, facilitating the informationalization of the national economy and social services.

According to a report in Xinhua net, which belongs to the official Xinhua News Agency, in July of 2002 , China passed a special programme to promote social and economic development through the wider use of information technology. Efforts are called to apply information technology in every field of social and economic development through improved IT infrastructure and make better use of the existing Internet resources.

Under the direction of the policies, China's information industry has now become the pillar of the country's economy. In the past decades China has developed the world's 
largest telecommunications network. Its 397 million telephone users, 90 times that of 1989, have turned China into the biggest telecom market in the world.

Chinese government's efforts to popularize the Internet are reflected in launching government online project, promoting e-commerce and encouraging the use of the Internet in education.

In January of 1999 , the Chinese government started the government online project. It hopes that the project can help streamline governmental organizations at different levels, reduce administrative costs and enhance transparency as well as offer more channels for better communication between the public and government. The government online project www.gov.cn has helped 60 percent of the departments in central government go online. And the provincial and municipal governments that go online under the gov.cn domain have reached 2,400 . By surfing the websites people can obtain more and more useful and timely information, including the full text of Chinese law and regulations, many of which were confidential and unpublished in the past. The Chinese government turns the Internet into an effective means of spreading information about national policies and establishing new image among people.

As a country that focuses on economic development, the Chinese government is more concerned with economic calculation in the process of policy-making. At present the Chinese government gives priority to creating an environment that is beneficial to economic development and encouraging investment. The better use of the Internet in business accords with the government's long-term strategy and becomes the prerequisite for the country to remain competitive. As part of its plan the Chinese government is also implementing the enterprises online projects, hoping the Internet can help establish 
modern enterprise system in the country and introduce its enterprises to the world. The economic specialists in China note that the greater the Internet access, the faster the economic growth. According to the estimate made by the economists with the International Data Corporation Asia Pacific, China will lead the Asia Pacific online trading in the next five years. By 2005,22 percent of all online trading accounts of the region will be in China.

Chinese government's decision to expand the Internet in the country also derives from its recognition of the Internet's great potential as an instrument of raising the educational level and improving the quality of its people.

In December 1993, the Chinese government decided to build the China Education and Research Network (CERNET). The final objective of CERNET is to connect all the universities and institutes in China. By linking to the global Internet, CERNET can connect the universities and institutes in China with every corner of the world, which will offer them an easy access to the valuable scientifie and technological resources in the world.

At present the Internet has an important role in delivering distance education. The Ministry of Education in China plans that five million college students will use online education by 2005 . In addition to that the Internet is changing education from a teachercentered to a student-centered activity. 


\section{Chapter Two: Examples of the Strict Control and Policy Issue}

"The linking of the world's people to a vast exchange of information and ideas is a dream that technology is set to deliver. It will bring economic progress, strong democracies ... and a greater sense of shared stewardship of our small planet." - Vice President Al Gore (Adonis, n.d.; Geoggry, 1998; Einhorn, 2002)

\subsection{What does the Internet bring to us?}

"The new technological revolution or information revolution ... may help China skip over some of the stages which have been experienced by other developing countries."

- Then-Premier Zhao Ziyang, 1983 (Hamrin, 1990; Einhorn, 2002)

"None of the four modernizations can be achieved without the application of information."

- President Jiang Zemin, 1996
(Foreign Broadcast Information
Service Daily Report [FBIS], 1996,
February 22a, 22b).

Freedom of information is enhanced by the Internet. It directly goes from hand to keyboard. Everything from Hollywood gossip to details about a government's latest legislation is just a few clicks away when you are online (Kneteman, 2003). 
This attribute of the Internet determines that it functions as a repository of ideologies, images, and information. Also, the Internet permits its users to interact with each other by way of e-mail, messenger, and chat rooms. There are no geographic barriers or cost differentials, whether people converse with someone next door, across the country, or halfway across the globe. This attribute of the Internet has appealed to a wide range of countries along the economic spectrum eager to improve government and business services, increase information flows to administrative agencies, and facilitate scientific research (Einhorn, 1002).

Institute for High Energy Physics (IHEP) director Xu Rongsheng stated that, because of the Internet, "[Chinese scientists] are now able to send messages, publish papers, prepare for conferences and exchange ideas with their foreign colleagues in a faster and more reliable way" (FBIS, 1994, September 16; Einhorn, 2002).

Li Xing, the lead architect of CERNET, stated, "If China doesn't have this information technology that we are developing here, then China cannot develop" (Johnson \& Liu, 1995; Einhorn, 2002).

Attracted by the economic, scientific, and educational potential of the medium, the Chinese government formulated plans to connect China with the Internet in the early of 1990s. The "route to development in the future world" was going to be tied to the Internet, which was envisioned as becoming integral to the functioning of a modern economy. Government officials expected that their investment in computers, modems, and high-speed connections would permit China "to share information freely and enable the country to fully join in the worldwide sharing of information and high technology" (FBIS, 1994, September 16, November 30; Einhorn, 2002). 


\section{$\underline{2.2 \text { Dilemma }}$}

All governments, no matter whether they are non-democratic or democratic, have been attracted by the economic and technological promise of the global information superhighway. The benefits brought by the Internet are undeniable. It is a powerful and vital economic, educational, and political resource but, indeed, it can be a double-edged sword. The Internet not only contains scientific and business information but is also a global repository of banned texts, a forum for wide-ranging political discussions with unlike thinkers, and a vast source of news and opinions (Lewis, 1994; Kantrowitz, 1994; Taubman, 1995). Thus, the Internet content creates a threat for some democratic and nondemocratic regimes. Einhorn says that "the content-saturated Internet can create conditions of ideational pluralism, defined as a situation in which multiple sources of ideas, images, and news are widely accessible to the public. When it becomes commonplace for the citizens of a particular state to have access to a greatly expanded quantity of news, facts, and ideas, governments will face greater difficulties in maintaining their hegemony over the distribution of information and ideologies in the domestic arena. Ideational pluralism and the subsequent loss of hegemony can represent a significant political threat to nondemocratic regimes whose legitimacy and hold on power depend on a tame domestic ideational climate." (Einhorn, 2002)

What the Internet brings to us is more than its multi-faceted content. The vast communication capability available to Internet users is another vital feature of the Internet. Media, such as telephone, radio and photocopier, creates a threat to nondemocratic governments but the Internet "possesses even greater potential than earlier 
technologies to create politically consequential public spaces that challenge the preeminence of some non-democratic regimes" (Einhorn, 2002).

Many countries have already identified the negative consequences resulting from the Internet. Some countries including the United States, Germany, Singapore and China have already taken measures against cyberspace pornography. Einhorn points out:

"The scope of and ease in obtaining information on the Web, as well as the communication capabilities available to users, provide the means for undermining the pillars of non-democratic rule. The decentralized nature of the Internet complicates the task of state control of this medium. Nevertheless, despite the risks that may exist from joining the global computer network, non-democratic regimes have not shunned this technology because they regard it as the key to development, prosperity, and influence. Instead, they have embarked on strategies of containment." (Einhorn, 2002)

He further argues that while all countries may fear that the moral climate will be harmed by societal interaction with the Internet, non-democracies have additional worries about the political consequences of unfettered domestic access to the World Wide Web and e-mail.

So, the application of the Internet has been uneven. On the one hand, nondemocratic regimes encourage and assist the development of the Internet; on the other hand, they take efforts to regulate this medium simultaneously. This is the case with the Chinese government. The Chinese government feared that losing control over the Internet could probably lead to unfavorable and unexpected ideological change. As a result, "despite wanting to take advantage of this powerful information and communication tool, the Chinese government has not fully embraced the new technology. In fact, because of this concern about an influx of ideas, information, and images and its effect on the 
continued incumbency of the $\mathrm{CCP}$, the government has implemented measures that are meant to tame the Internet but could hamper its full utilization." (Einhorn, 2002)

\subsection{Examples}

For years, people have known that Beijing has been censoring the Internet. Two Harvard researchers, Jonathan Zittrain, the Harvard Law School professor, and Ben Edelman, a first-year student, conducted an experiment in the summer of 2002 to find out who is on the Beijing's Internet blacklist. According to Zittrain, you can easily type a website address into the program and see whether it is accessible in China. Zittrain says he and Edelman were "agog" to discover that www.uscourts.gov, the website of America's federal court system, was off-limits. But not all U.S. government sites are taboo. "Whitehouse.gov is accessible," Zittrain says. Not only is President Bush's site accessible, but so too is Secretary of State Colin Powell's, since according to the Harvard duo's program, the State Department's website is not banned. But, Zittrain adds, not all U.S. government offices are so fortunate. The Voice of America's site is taboo, Zittrain reports. Academia can be blacklisted too: Stanford University's and New York University's sites are off-limits. In early September of 2002, they announced the first batch of websites that they had determined were banned in China. Besides the predictable pomographic, prodemocracy or religious websites, the list included major U.S.-based news outlets, universities and government organizations.

Another example comes from $\mathrm{CNN}$ news. Lisa Rose Weaver, a $\mathrm{CNN}$ correspondent reported on September $6^{\text {th }}, 2002$ that a few days after the Google search engine was blocked, Chinese Internet police blocked a second search engine, AltaVista, 
in an effort to eliminate pornography and "unhealthy material" from reaching Chinese citizens online. Since both Google and AltaVista are U.S.-based companies, this move marks an escalation of policy that once applied only to locally-based Internet companies, according to Weaver. According to the news service, Weaver further reported, China would not allow search engines to become "vacuum cleaners" which in discriminately suck in information without a filter. It added that Internet users and Internet service providers (ISPs) had demanded measures to eliminate pornography and "unhealthy materials" - a phrase that usually refers to political views not shared by the Communist Party.

Although after that there is a news report indicating that the Chinese government has unblocked Google, the banning of these two popular neutral net surfing engines is not good for the image of Chinese government.

\subsection{Policy Analysis}

"We need to be selective. We hope to restrict as much as possible information not conducive to China's development."

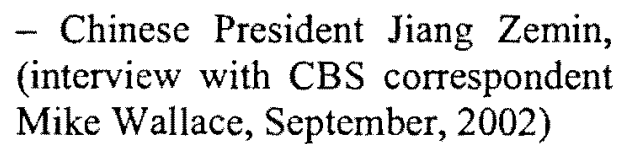

Since the Internet was introduced into China in the late of 1980s, the Chinese government has taken a positive and reasonable attitude towards its growth in China, because it benefits both the ordinary people and the government. The entire effort is aimed at promoting economic and social development, which in turn will serve the needs of the government in maintaining the legitimacy of the existing political and social 
systems. At the time that the government hails the advantages of the Internet, it takes measures to counter the negative sides and political impact of the Internet. It is clear that the government will never overlook the political risks brought by the Internet.

Lorimer states: "The mass media are a vital link in an information system that encompasses all levels of society and its governance. But just because the mass media are a vital link between government and people, contributing to both the political life and the general character of society, it does not follow that they are neutral conveyors of information. The mass media are social institutions that function within particular political and legal constraints" (Lorimer, 1994). Operating within the specific political and social systems in China, the Internet is destined to function under the direction of the $\mathrm{CPC}$ and the government.

In fact the Chinese government has worked out a guiding policy on the Internet, which is elaborated as taking vigorous measures for its expansion, strengthening management, seeking advantages and avoiding disadvantages. The Chinese government is cautious about the flow of information in the Internet, and determines to minimize the risk from it.

In terms of intensifying efforts in the management of the Internet, the Chinese government mainly depends on formulating regulations and rules. Analysis of these documents reveals that the Chinese government is indeed concerned about national security.

In 1994, the State Council issued the "PRC Regulations for the Safety Protection of Computer Information Systems", which states that any computer information system should not put national security in danger. It also assigns the Ministry of Public Security 
the responsibility for monitoring the Internet "to supervise, inspect and guide the security protection work ... investigate and prosecute illegal criminal cases ... and ... perform other supervising duties".

In 1997, the Ministry of Public Security issued a new regulation called "Computer Information Network and Internet Security, Protection and Management Regulations" and which came into force on December $30^{\text {th }}$ of that year. The new regulations contain five chapters and 25 articles. The document focuses on managing the security of domestic and international computer information network connections which outline the duties and responsibilities of China's Internet service providers and punishments for Internet use to leak state secrets, damage state interests, threat state security or distribute harmful information. Although reported outside of China as a "crackdown" on Internet usage, the new regulations contain no new prohibitions, and go beyond the previous interim Internet regulation only in the level of detail regarding procedures, responsibilities and penalties for violators.

In September of 2000, the Chinese government issued two sets of regulations: "Telecommunications Regulations of the People's Republic of China" and "The Measures for Managing Internet Information Services". The former covers a much broader range of issues including ownership, content and other aspects of the Internet usage, while the latter regulates Internet services and promotes the "healthy" development of these services.

Article 15 of "The Measures For Managing the Internet Information Services" states that the Internet information service providers are prohibited to make, duplicate, issue, or disseminate information containing the following: 
(1) Material that opposes the basic principles established by the constitution;

(2) Material that jeopardizes national security, reveals state secrets, subverts state power, or undermines national unity;

(3) Material that harms the prosperity and interests of the state;

(4) Material that arouses ethnic animosities, ethnic discrimination, or undermines ethnic solidarity;

(5) Material that undermines state religious policies, or promotes cults and feudal superstitions;

(6) Material that spreads rumors, disturbs social order, or undermines social stability;

(7) Material that spreads obscenities, pornography, gambling, violence, murder, terror, or instigates crime;

(8) Material that insults or slanders others or violates the legal rights and interests of others;

(9) Material that has other contents prohibited by laws or administrative regulations.

The same content also appears in Article 57 of the "Telecommunications Regulations of the People's Republic of China". Regulations also cover Bulletin Board Systems (BBS). Under the regulations the BBS service providers have an obligation to monitor contents in BBS and delete any thing that violates the provisions in the regulations. 
On January $21^{\text {st }}, 2001$, the Supreme People's Court ruled that those who cause "especially serious harm" by providing "state secrets" to overseas organizations and individuals over the Internet may be sentenced to death (Amnesty International, 2002):

\begin{abstract}
"Those who illegally provide state secrets or intelligence for units, organizations and individuals outside the country through Internet with serious consequences will be punished according to stipulations of the Criminal Law ... in especially serious cases, those who steal, make secret inquiries or buy state secrets and intelligence and illegally provide gathered state secrets and intelligence to units outside the country will be sentenced to ten or more years of fixed-term imprisonment or imprisonment for life and their properties may concurrently be confiscated by the state. In cases of a gross violation of law and where especially serious harm is caused to the state and people, law offenders may be sentenced to death and their properties will be confiscated by the state." (Xinhua News Agency, January 21, 2001)
\end{abstract}

In January of 2002, the Ministry of Information Industry announced new regulations that require Internet Service Providers (ISPs) to monitor more closely people's use of the Internet. Software should be installed to ensure that messages are recorded and if they violate the law the ISPs must send a copy to the Ministry of Information Industry, the Ministry of Public Security and the Bureau for the Protection of State Secrets. (Amnesty International, 2002)

In addition to these regulations, Chinese Internet operators have also worked out a Public Pledge on Self-discipline for China's Internet Industry, whose main aim is to promote Internet use, prevent cyber-crime, foster healthy industrial competition and avoid intellectual property violations. The signatories agree to conduct self-censorship in the content of their sites and follow the regulations set by the Chinese government. Figures released by the official Guangmingnet in November 11 of 2002 show that more 
than 1,200 Internet businesses in China have voluntarily signed the pledge. The pledge makes the Internet operators responsible for the consequences arising from offering any harmful and subversive content. 


\section{Chapter Three: Technology Aspect of the Internet Control}

"From a technical point of view, the Internet is a packet-switched network, meaning it is designed so that data are sent around in small packets and are able to take another route if one part of the network is down. Censorship is thus treated as if one part of the network is down. The Internet will find a way around the censorship to reach its target. People with sufficient technical knowledge always will find a way to reach the blocked information. However, as the Internet population grows, the majority consists of users that do not have the required technical knowledge." (Tsui, 2001)

By the end of September 2001 , there were ten network operators ${ }^{1}$ and around two hundred Internet Service Providers (ISPs) in China. All these ten network operators can connect to the outside world and the total international export bandwidth had achieved $5,724 \mathrm{MB}$ by the end of September 2001 (See the graphic below, not including CGWNET and CSNET).

\section{International Export Bandwidth \\ (Unit: MB) \\ (End of September, 2001)}

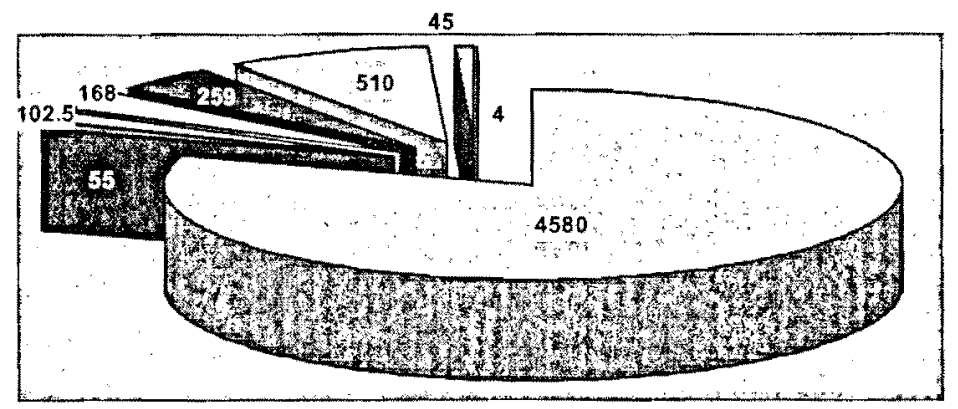

口CHINANET

I. CSTNET

$\square$ CERNET

$\square$ CHINAGBN

UNINET

$\square C N C N E T$

- $C M N E T$

$\square$ CIETNET

Source: CNNIC

The network international export bandwidth increased quickly. By the end of 2002, the total bandwidth in China had achieved 9,380MB and the connected nations include the United States, Canada, Australia, Britain, Germany, France, Japan and Korea. 
Currently, seven network operators share this bandwidth. The bandwidth distribution is shown in the following chart:

\section{International Export Bandwidth \\ (Unit: MB) \\ (By the End of 2002)}

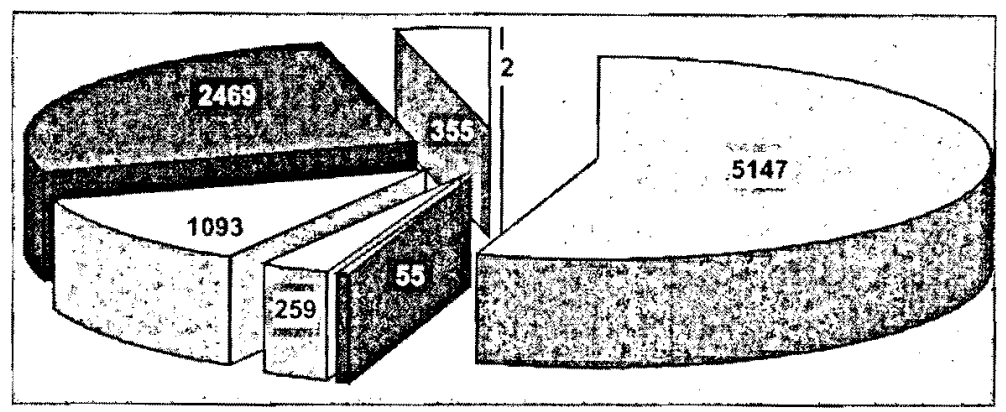

DCHINANET

- CSTNET

口CERNET

口UNINET

- CNCNET

DCMNET

gCIETNET

Source: CNNIC

Other domestic network ISPs need to use the International bandwidth run by these network operators to provide Internet services to their end-users (family and commercial clients). Albeit these network operators have their own international network exports connecting to different nations and regions, in physical distribution, the locations of the exports are fixed. For example, according to CNNIC, by the end of 2002, the international export bandwidth owned by CNCNET had been $2,469 \mathrm{MB}$, among which 1,442MB for the United States, 90MB for Japan, 180MB for Korea, 45MB for Singapore, $90 \mathrm{MB}$ for Taiwan and $622 \mathrm{MB}$ for Hong Kong. But from physical locations, only three cities, Beijing, Shanghai and Guangzhou, have the international exports. Beijing and Shanghai share the bandwidth that connects to the United States while Guangzhou owns the export connecting to the Asia Pacific area. (See the chart below) 


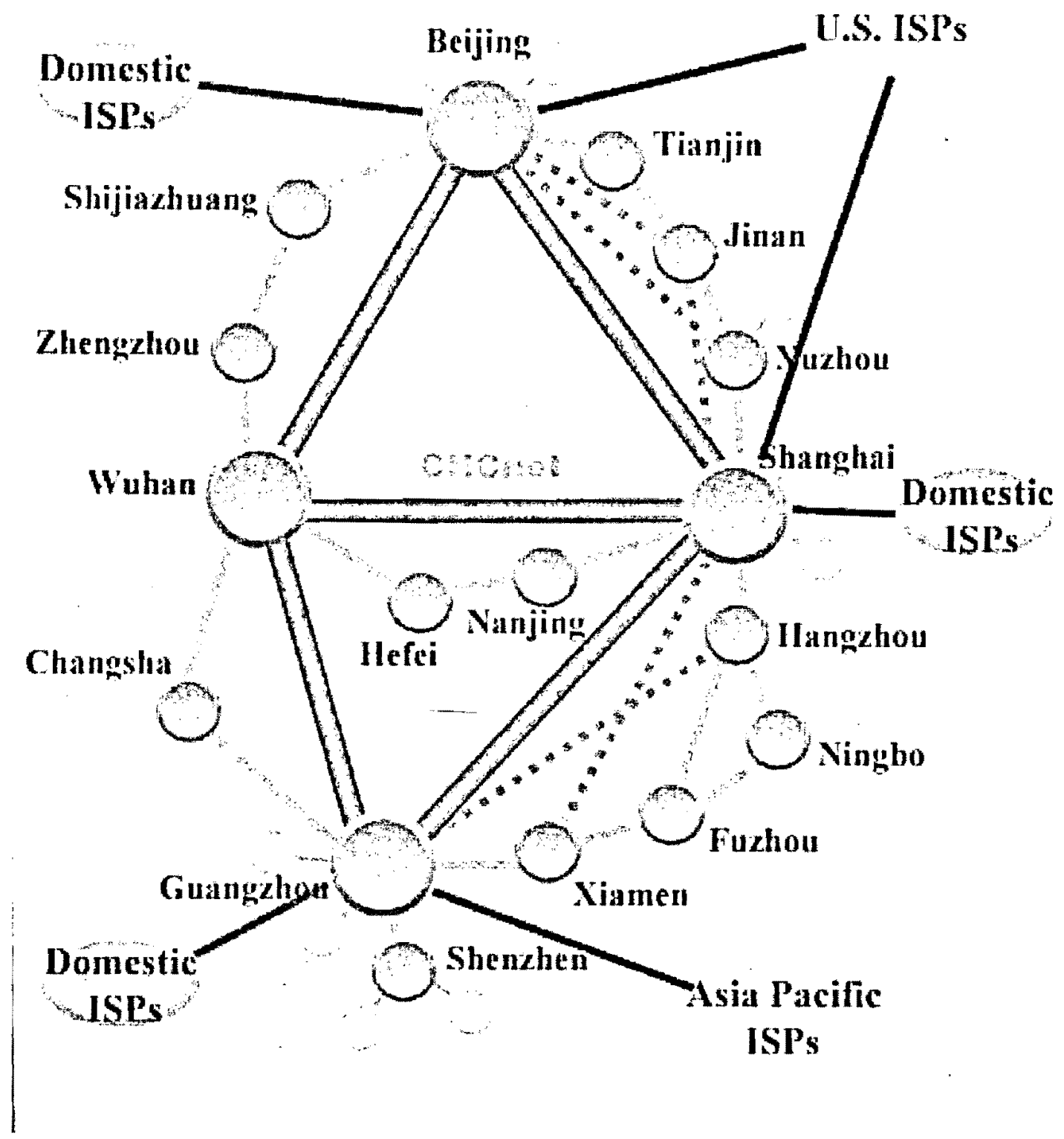

Source: www.enc.nct.cn

Another example is China Education and Research Network (CERNET). CERNET is the first nationwide education and research computer network in China. The CERNET project is funded by the Chinese government and directly administrated by the Chinese Ministry of Education. It is constructed and operated by Tsinghua University and 
other leading universitics. CERNET has already owned 28 international and regional channels connecting to the United States, Canada, Britain, Germany, Japan and Hong Kong. The total bandwidth had been 259MB by the end of 2002 (CNNIC, 2003). Over 900 organizations in China connect to CERNET, including universities, colleges, middle schools and other education and research institutes. There are 1.2 million host computers and over 8 million individual users. Albeit CERNET has numerous users and a wide coverage, it only has one international export physically which locates in the networking center of Tsinghua University in Beijing.

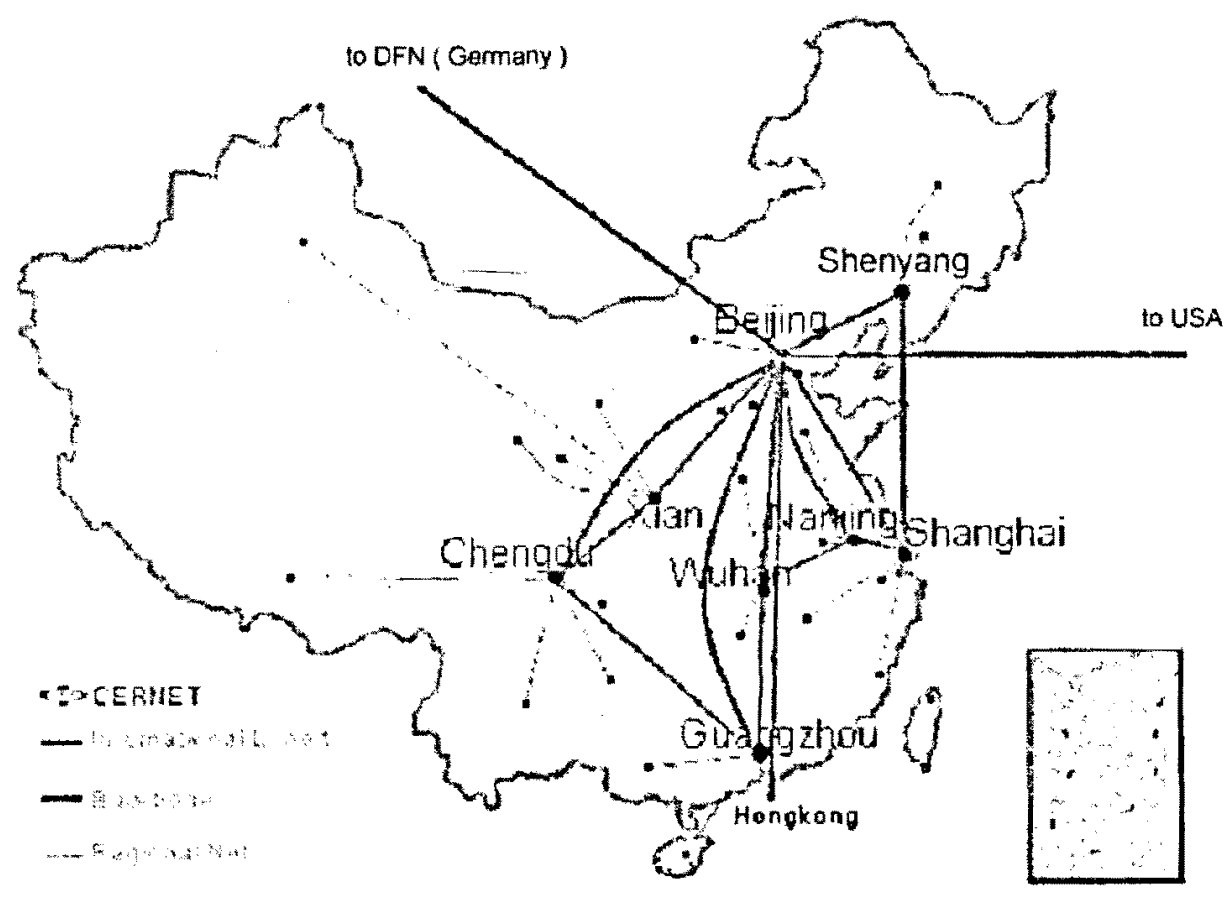

Source: www.cdu.cn

All the Chinese "netizens" (including domestic ISPs who provide Internet connection services) need to access the Internet via these Internet operators. Although the Chinese government is not able to control the overseas websites and servers, it can bring 
the overseas information under control by administering the international exports of these network operators. There are two main methods of doing this: positive website blocking, and negative message filtering.

\subsection{Website Blocking}

"The authorities routinely block news sites, especially foreign-based sites, including those featuring dissident views or banned groups. The blocking appears to be intermittent but more prevalent at times of heightened security such as the anniversary of the crackdown on the 1989 pro-democracy protests, the annual meeting of the National Party Congress or visits from heads of state or government." (Amnesty International, 2002)

An important government measure to realize the Internet control is to control the main infrastructure (Tsui, 2001). Since all the users need to connect to the Chinese network operators if they want to access parts of the Internet that are not within China, these network operators thus create an "Intranet" in China. Not only do these network operators control the information within China, but they also control the network traffic that travels outside China. So, when the government wants to manage the information access on the Internet, it only needs to control the international exports of the Chinese network operators. When there is an undesirable website existing, the government can just simply block the IP (Internet Protocol) number of the web page on the international exports of these network operators. This is a direct blocking and it works like this: when you connect to the Internet, you cannot access certain sites because IP number of the web page has been blocked on the exports. Since traffic has to pass through the gateway of the 
Chinese network operators and the IP address of certain website server is blocked at the gateway in an Access Control List (ACL) (Amnesty International, 2002), you will not be able to access the certain website. A direct blocking is usually placed on the websites which are considered containing harmful content to Chinese government, such as the Voice of America website and the Falun Gong websites. But since a direct blocking usually brings Chinese government a not-so-good reputation, three indirect methods are usually used instead of the direct blocking: disruption of domain name parse, replacement of domain name, and blocking messages from the undesired websites.

\subsubsection{Disruption of Domain Name Parse}

Usually, the address of a certain website is composed of two parts: IP number of this website and domain name of this website. Most 'netizens' surf the Internet by simply inputting the domain names of the websites. So, for the users who are unfamiliar with the IP addresses of the website servers (website server is the computer which physically contains the website), the simplest method to restrict the access to the undesirable websites would be to control the domain name servers (DNS) and to remove the websites from the backbone's DNS. It would prevent the netizens, who only remember the domain name of a certain web page, from typing the domain name of a certain website and being able to access it. When the domain name is removed from DNS, the connection between the IP number of the website and domain name of the website is lost. In other words, the domain name parse is disrupted. Without domain name parse, the router cannot find the exact IP address of the website server according to the domain name of a certain website. 


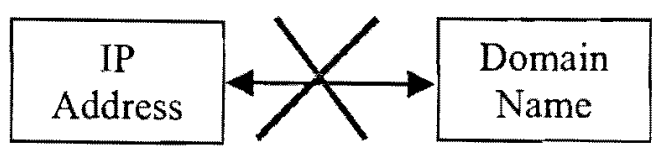

The deficiency of this method is that it does not take effect for the users who are familiar with the IP address of a certain website server. For example, in summer of 2002 , the Chinese government blocked the well-known searching engine Google. When the users type in the domain name of Google (www.google.com) into the address box of Internet explorer, the message "This page cannot be displayed" would appear. But if the users know to type the IP number of Google (http:/216.239.33.100) into the browser and this will provide access to Google because the IP number of the website has been used directly and the DNS bypassed.

\subsubsection{Replacement of Domain Names}

Replacement of domain names happens when it is not advantageous for the government to block the undesired websites directly. The government then takes measures to influence the normal domain name by parsing and replacing its default IP address by other websites'. For example, during the period of Google's blocking in China, when the users requested Google site by typing in its domain name (www.google.com), they were redirected to other searching websites including Openfind, Globepage, Chinaren, search.online.sh.cn, fm365, and the sky net of Peking University. That means the connection between Google's domain name and the IP address was cut and the domain name of Google referred users to other websites. 


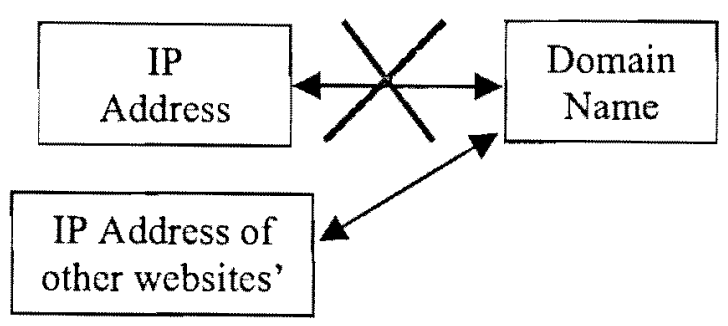

The screen shot below reflects a redirection from Google to the sky net of Peking University.

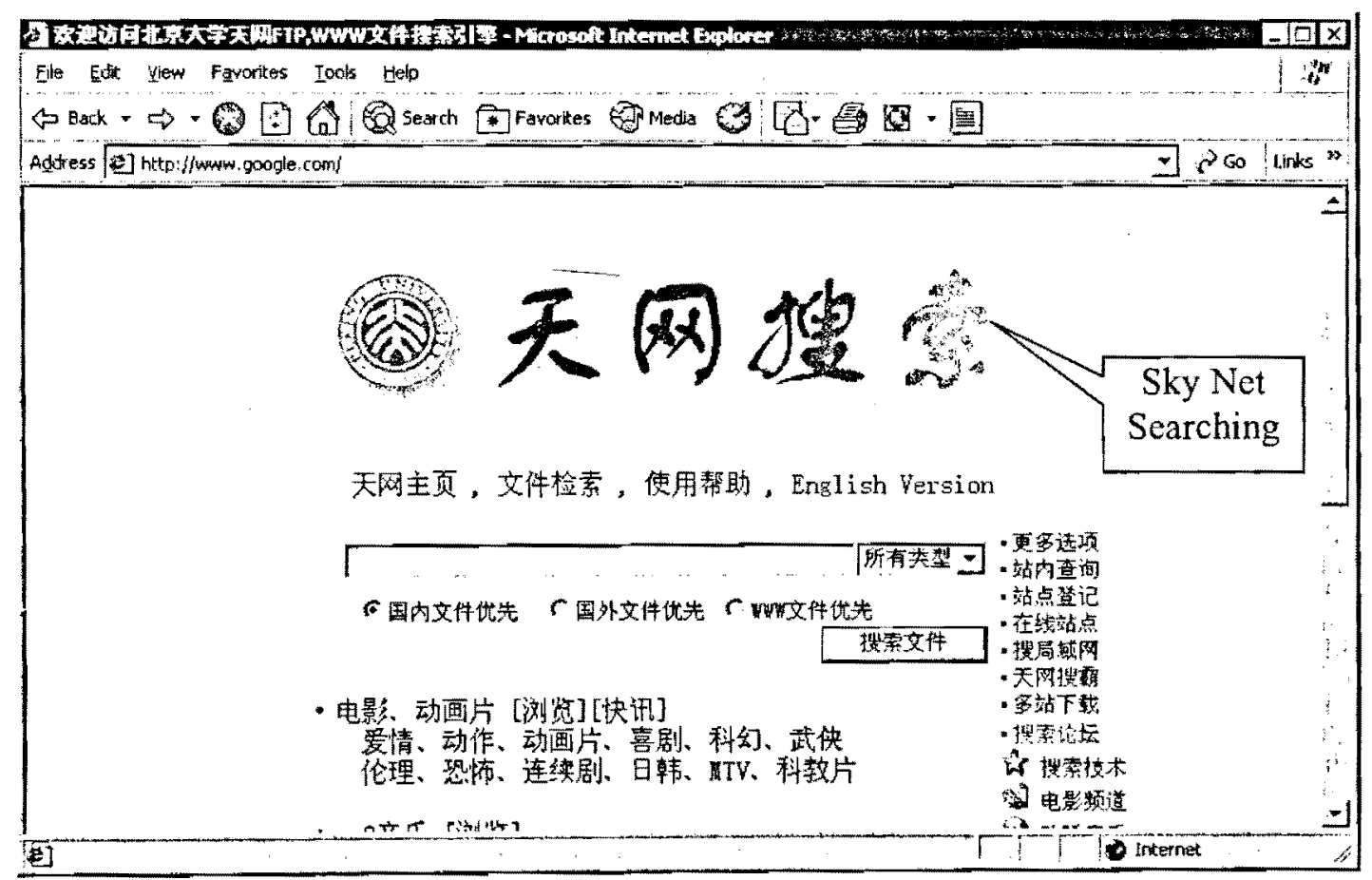

3.1.3 Blocking messages from undesired websites 


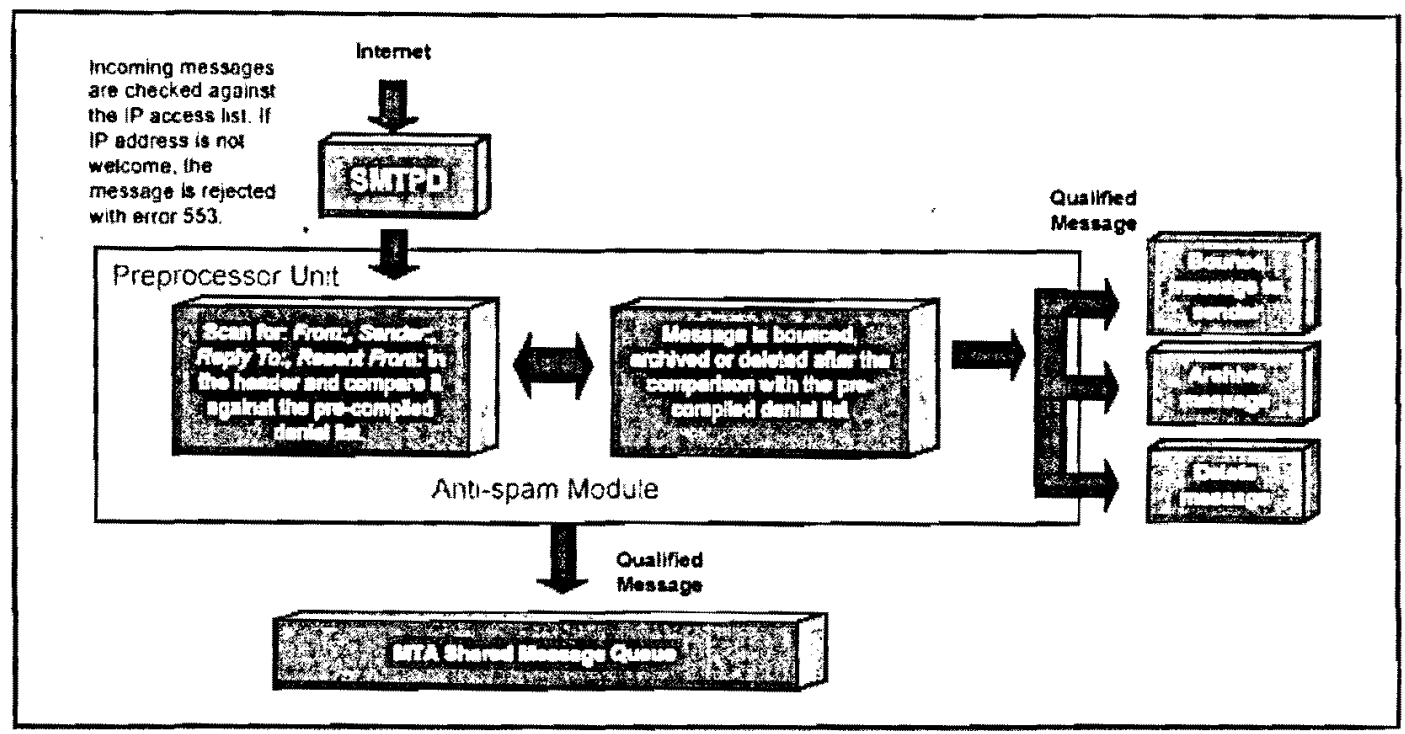

(Source: International Messaging Associates, 2001)

Besides the control of certain websites, messages from some insecure networks are also being checked. Usually, unsolicited or spam messages originate from known networks. "These networks are either owned by spammers or by careless service providers. If the network addresses of either the spammers' machine or network (range of addresses) are known, Simple Mail Transfer Protocol Daemon (SMTPD) shuts down the connection request (with an error code 553) before the SMTP transaction starts. Internet Exchange allows the system administrator to create a list of all the IP addresses or IP address ranges that are authorized to send messages to Internet Exchange. If the SMTPD receives a connection request from the remote host whose IP address is not included in the list, SMTPD automatically deny the connection." (IMA, 2001)

\subsection{Filtering}

Besides blocking, filtering is another effective way to restrict the information access on the Internet. There are two main methods in filtering, one is to use the technology of firewall, and the other is the packet keyword filtering. 


\subsubsection{Firewall}

Firewalls are a powerful filter for undesired messages. It is "a system designed to prevent unauthorized access to or from a private network. Firewalls can be implemented in both hardware and software, or a combination of both. Firewalls are frequently used to prevent unauthorized Internet users from accessing private networks connected to the Internet, especially Intranets. All messages entering or leaving the Intranet pass through the firewall which examines each message and blocks those that do not meet the specified security criteria." (Walton, 2001)

As Zhou illustrates, three types of firewalls are being used now:

- "In general, a passive firewall is placed just between the internal trusted network and the external distrusted network. The firewall, often uses proprietary, non $\mathrm{TCP} / \mathrm{IP}$ based protocols, acts as a chokepoint that monitors the information flowing through it, and rejects application-level network traffic (see the figure below)

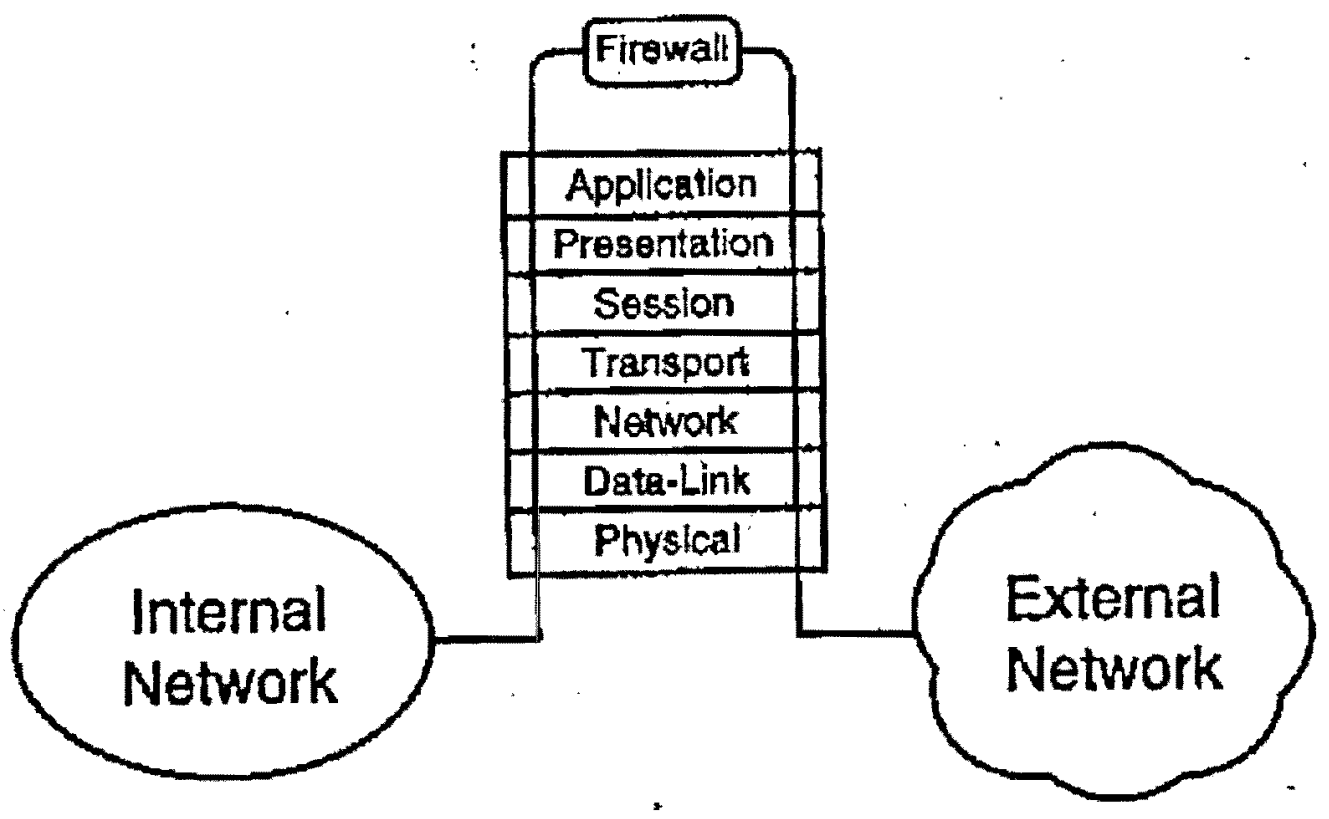


- Also, firewalls can operate at the network and transport layers, in which case they examine the IP and TCP (Transfer Control Protocol) headers of incoming and outgoing packets, and reject pass packets based on the programmed packet filter rules. There are two kinds of technologies that can be used for this operation.

(1) Application Gateway

Internal Network $\leftrightarrow$ Application Gateway $\leftrightarrow$ External Network

In this program, the Application Gateway uses the specially written code for each specific application for filtering. It examines and interprets the data within the packet header. It can also hold host names and IP addresses, enabling outsiders to only see the gateway. A physical application gateway uses proxy servers, codes which represent both clients and servers. This is the most flexible and secure one in these three kinds firewalls. By adopting the Internet Communication Agreements - TCP/IP, the Proxy Gateway controls the visiting abilities of both the internal and external networks.

(2) Packet Filtering

$$
\text { Internal Network } \leftrightarrow \text { Router } \leftrightarrow \text { External Network }
$$

The Router is able to determine whether to let packets go through based on the TCP/IP headers information such as packet source and destination addresses which are compared to an access list. If the addresses of the packets are in accordance with the access list, the router will deliver the datagram to its final destination. Then this technology can be used to prevent the unwelcome visits between the internal and the external networks. 
- A Circuit Level Gateway can be used as a firewall too. Commonly a Circuit Level Gateway relays TCP connections. The visitor from the external networks connects to the gateway and specifies the desired destination and service. The gateway checks to see if the connection is allowed and if so it will make a connection with the destination using a different IP address. The gateway then removes the IP information and passes only the TCP information between the internal and external networks." (Zhou, 2000)

So, at the international exports of ten Chinese networks, the Chinese government sets up the firewall to have the incoming messages checked. As shown in the graphic below, the firewall functions like a red brick wall. Although it is not the exactly similar, firewall is the protecting gateway for the Internet networks. "This firewall server acts as a buffer between all of your servers and PCs in the outside world. This provides you with a protection from the crackers and keeps your network safe. This firewall is there to block all suspicious incoming traffic from the outside world. This setup is very secure because the internal network is completely shielded from attacks." (Zhou, 2000) 


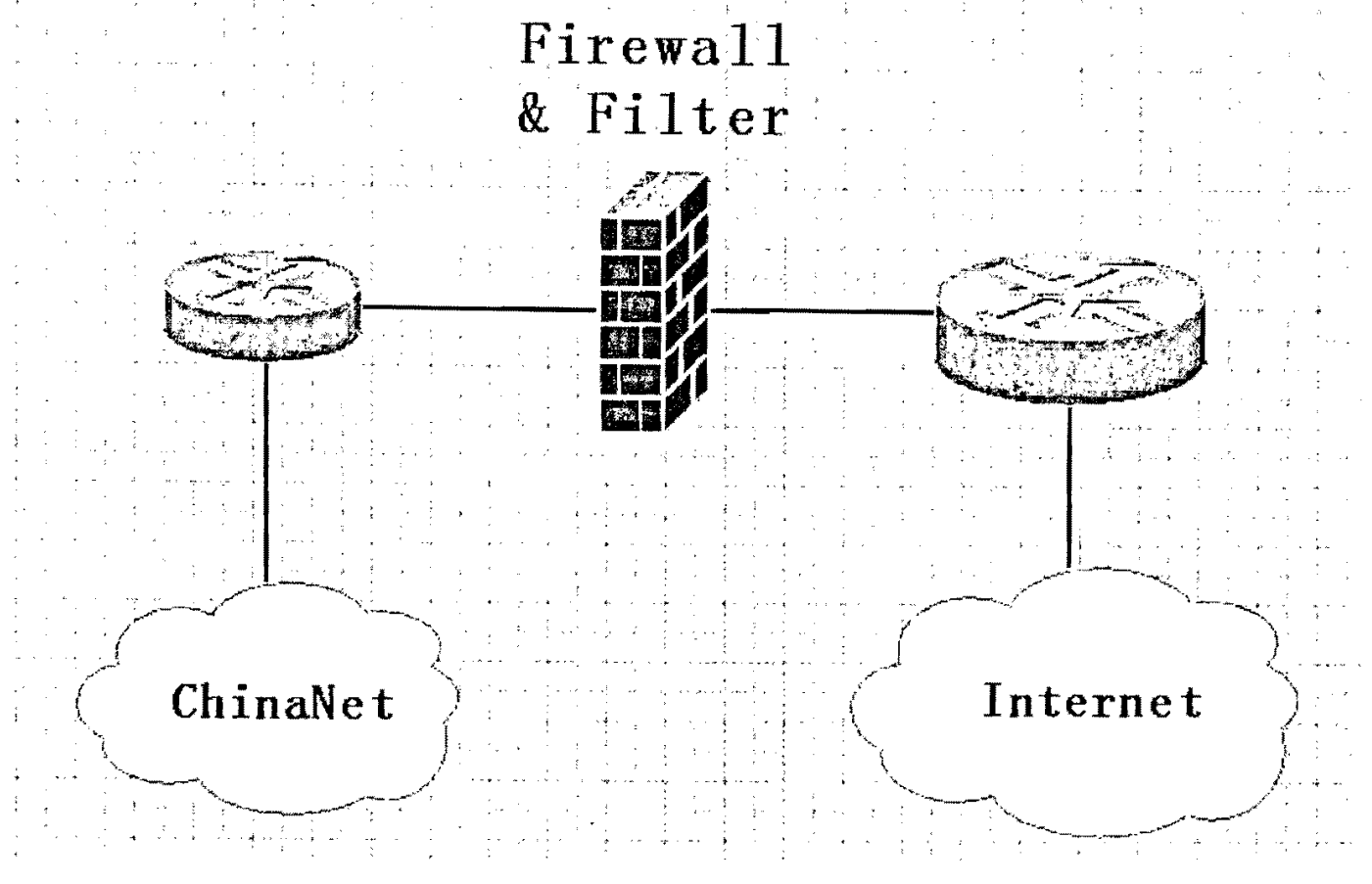

\subsubsection{Packet keyword filtering}

The second commonly used method in filtering is packet keyword filtering. It can effectively filter the sensitive content on the Internet. Packet keyword filtering is achieved by way of network listening. Network listening is a method to set up hardware equipments at the network exports and to direct all the data packets into one computer or a computer cluster system. Then the IP datagram, TCP datagram and the datagram on the application layer, which delivers the exact information such as a HTML web page, can be obtained. If a certain HTML web page contains one or more sensitive keywords, it would be defined as a sensitive web page and will be delivered to the webmaster for further checking automatically. The webmaster then intervenes the transfer of this web page and the end-users cannot access to this page. The software of keyword filtering could be installed at the international exports of the network operators, in the service system of 
every ISPs or inside the user's computer. The screen shot below is an example of keyword filtering. Since the word "hustler" is defined as sensitive word, the web page is then prohibited from accessing.

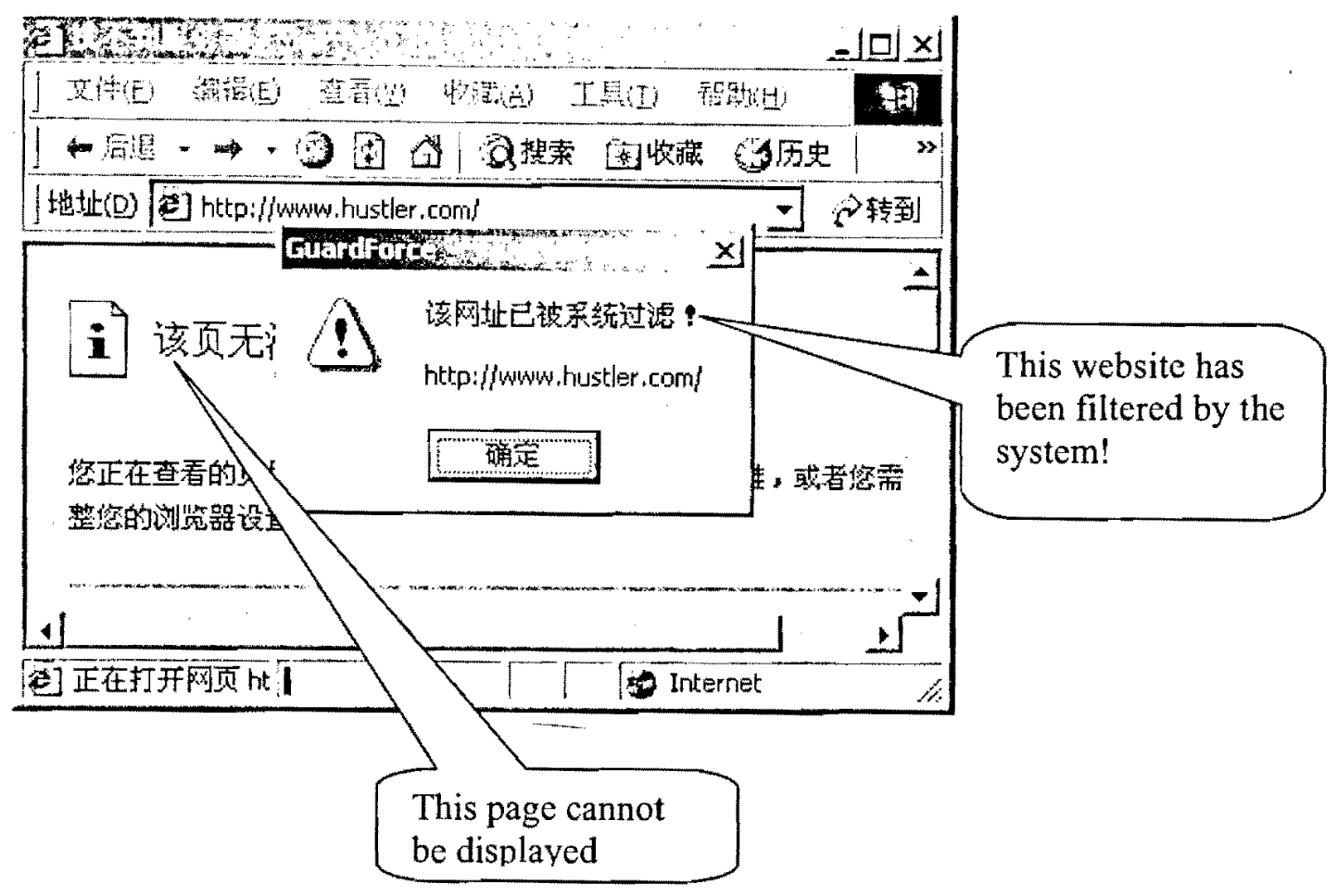

So, from the technology point of view, the Chinese government uses these abovementioned methods to regulate the information in the Internet. Not only the websites are being checked, but also the e-mails and messages on BBS are under management, because all the services on the Internet are used by dissidents, Falun Gong practitioners, Tibetan exiles and others to circulate information or protest against repression. In 2002, thousands of Internet cafes throughout China have been forced to close and those that remain are obliged to install software which filters out more than 500,000 banned sites with pornographic or "subversive" elements (Amnesty International, 2002). At the time being, although the Chinese government is accelerating the construction of the 
information superhighway infrastructure in China for economic purposes, it will not loosen the control on the information transmitted by the Internet and will not allow the dissentient opinions on politically-sensitive issues to develop freely without any regulation. 


\section{Chapter Four: The Difficulty of Controlling the Internet}

\subsection{Many countries restrict the Internet}

Not only China controls the Internet, many other countries also have the similar regulations and share the technologies on Internet control used by China.

In Vietnam, a country of 70 million people and only approximately 60,000 computers, the control on the Internet is also strict. The control is intended to sustain the governmental ideology. When the Vietnamese government began to open its doors to accelerate its economic development, abundant information technology flew in. Pham Dao, director of the state-run Vietnam Datacommunications Company, has "caused concern" by proposing that this organization be the "nation's sole gateway to the Internet, giving the company the authority to license service providers and potentially limit use through high prices (Wilhelm, 1996; Rogerson \& Thomas, 1998). The Vietnamese government would like to "regulate but not shut down" Internet services. "When we start to open our door, we find that fresh air and dust come in," says Dao. "We would like to keep the fresh air and prevent the dust" (Wilhelm, 1996; Rogerson \& Thomas, 1998).

In March 1996, the government of Singapore also announced broad policies of Internet control, stating that it would "hold both content providers and access providers responsible for keeping ... politically objectionable material out of the country's 100,000 Internet accounts" and this action indicates that Singapore is attempting to solidify its status as an "information and technology hub for the region" (McDermott, 1996; Rogerson \& Thomas, 1998). Although Singapore's economy leans more toward the free market than a managed one, and the desire for greater flow of goods is indeed present, Rogerson and Thomas point out the Singaporean government is clear that the free flow of 
information and ideas can be both beneficial and antagonistic to the government, and Singapore seems to place more emphasis on internal political control.

Control does not always mean restriction, said Rogerson and Thomas (1998). According to them, the Netherlands and Denmark also support the view that the government should regulate the flow of information in order to realize a more socialdemocratic society.

In Germany, the government also administers information on the Internet, especially content dealing with child pornography and neo-Nazis. On December 28,1995 , CompuServe, a global Internet access provider, blocked access to more than 200 sexually explicit computer discussion groups worldwide. This action came in response to an announcement by the German government that it would investigate the company on charges of violating the country's strict pornography laws (Markoff, 1995; Rogerson \& Thomas, 1998). Child pornography is illegal in Germany. Because of technical problems, CompuServe was unable to discontinue the service in Germany alone without affecting other countries. So, it finally denied access to more than 4 million customers in 140 countries. On January 28,1996 , Deutsche Telekom voluntarily blocked service to more than a million customers because the German government began to investigate the $\mathrm{T}$ Online service for the broadcast of anti-Semitic material. Because of historical reasons, racism is a very sensitive issue in Germany, and its strict anti-racist legislation reflects this inclination.

However, the content regulated by the Chinese government is not the same as that regulated by the governments in the west. The Chinese government usually puts its focus on politically-sensitive websites which contain pro-democratic information. According to 
Bill Dong, a spokesman for Dynamic Internet Technology Inc., the top ten forbidden websites are:

http://www.renminbao.com/

http://www.dajiyuan.com/

http://www.bignews.org/

http://www.creaders.com/

http://www.rfa.org/

http://www.internetfreedom.org/

http://www.voancws.com/

http://www.minghui.org/

http:/www.kanzhongguo.com/

http://www.pcacchall.com/

The information on these ten websites are either dealing with some dissentient opinions from the governmental ideology or about Falun Gong which is a banned cult in China. According to the investigation of Amnesty International, Lin Hai, a computer engineer from Shanghai, was arrested in March 1998 and is considered to be the first person to have been sentenced for the use of the Internet in China. He was accused of providing 30,000 email addresses to VIP Reference, a US-based online pro-democracy magazine, and charged with subversion and sentenced to two years in prison in June 1999 (Amnesty International, 2002). 


\subsection{Characteristics of the Internet}

The Internet is a "network of networks," a system of computers around the world connecting to each other via telephone and cable lines.

The first paramount characteristic of the Internet is its "borderless" nature. The Internet is borderless from its physical capabilities referring to the number and location of hosts, its location of users and the amount of information flow. This feature was first sensed by J.C.R Licklider, the first director of ARPANET, As described earlier, ARPANET, was the succinct description of Advanced Research Projects Agency Network, a computer networking program of the U.S. Department of Defense in 1969 , by which the Internet was envisioned. Licklider hoped to produce a "galactic network" of electronic communicating communities. But when his idea really came into reality, he and his colleague, Bob Taylor, found that the network would have a borderless nature: "What will on-line interactive communities be like? In most fields they will consist of geographically separated members, sometimes grouped in small clusters and sometimes working individually. They will be communities not of common location, but of common interest" (Press, 1992; Rogerson \& Thomas, 1998).

At beginning, there is only one network of hosts existing. As the technology further develops, a number of new networks came into being and thus the "network of networks" became the Internet as we know it today. "There is no one network known as the Internet; rather regional nets ... are all interconnected ... together into one great living thing, communicating at amazing speeds" (Kehoe, 1996; Rogerson \& Thomas, 1998). 
The second important characteristic of the Internet is the vast quantity of information located on the global computer network. Not only does an almost limitless amount of content exist in cyberspace - and the amount of on-line content is increasing at a dizzying pace - but users generally find it easy to explore a realm where the credo is openness, variety, and transparency (Taubman, 1998).

The high degree of anonymity and pseudonymity is the third characteristic of the Internet. Every 'netizen' could anonymously surf the web and use a pseudonym to chat with other users. It is common to adopt a nickname on the Internet and thus the real identification of people is hidden.

\subsection{The Difficulty of controlling the Internet}

The fatal point that makes governments in different countries fail in their attempts at controlling the Internet is the fact that the Internet is a prime tool for obtaining national wealth and power in the information age. Numerous countries have tied their economic development programs to the Internet because of the on-line availability of immense amounts of data. Although there are also many undesirable contents on the Internet, none of the governments can deny the huge benefits brought by the Internet. And government's dependence on the Internet means that there is still a huge volume of data flowing-in, which governments cannot fully control.

From a technical point of view, the Internet is a packet-switched network, meaning it is designed so that data is sent around in small packets which are able to take another route if one part of the network is down (Tsui, 2001). So, any governmental control of the Internet could only have affected those who lack technical knowledge. For 
those who have sufficient technical knowledge, they could always find a way to reach the blocked information.

None of the government measures described earlier could survive for long because of the decentralized nature of the Internet. Quite a few computer experts have noted that while the routes to the Internet can be controlled to some degree by the government, "you only need one [unauthorized entrant] and the damage will be done" (FBIS, 1995, May 25; Taubman, 1998). Moreover, as Fluendy observed, the technical measures can be circumvented by computer users who possess a high level of programming expertise (Fluendy, 1996; Taubman, 1998). When people want to view a web page which is banned by the local government, he or she can just log into the Internet and enter a foreign network run by other countries where the web page can be accessed. As long as there is still someone who can access to the banned page, the page cannot be banned completely.

When the Chinese government blocked the search engine Google in September 2002, Nart Villeneuve, 28, a University of Toronto computer science student, worked out an alternative way for Chinese citizens to access the mega-search engine. He created a Google-only proxy script which was not detected by the Chinese government, and "users were able to access a Web page at which time the script opened a connection to Google and from there it was business as usual", explained Villeneuve. He said, "all requests that the user makes to Google go through the Web server that the script is running, therefore the user's computer never directly accesses Google" (Kneteman, 2003). Even without enough technical knowledge, one could just simply ask a friend who has access to the 
certain page to download the page and email to him or her. It is a very simple way to view the banned web page.

Therefore, it is difficult for the government to block every form of content from the Internet since it can be transferred via other routes, using other protocols which can be copied at little cost. Web pages can be simply sent by e-mail, transferred by FTP (File Transmission Protocol), pasted on BBS (Bulletin Board System) and exchanged in any chat rooms. So, theoretically speaking, "if there is only one person or host who can access the content, that content can be shared over the whole network" (Tsui, 2001).

Furthermore, there are already hundreds of thousands different routes around the major nodes of the Internet. When one is blocked, messages are automatically channeled onto a different route. Since the government cannot block all routes, the banned message may appear in a different and perhaps uncensored site.

During the German government's investigation of the T-Online service of Deutsche Telekom for the broadcast of anti-Semitic material in 1996, the company did block the service to more than one million users. But, Hans Ehnert, a spokeman for Deutsche Telekom, also showed his company's incapability on forbidding all of the banned contents: "Of course we do not want to distribute neo-Nazi materials, but you cannot check all Internet pages" (Nash, 1996; Rogerson \& Thomas, 1998).

In their article "Law and Borders" which was written in 1996, Post and Johnson already discussed the futility of an existing government attempting to assert authority and control over the Internet due to the ease of escaping jurisdiction on the Internet. Even though, many countries, including the United States, Canada, Germany, China, Vietnam, Singapore, Britain, France, Holland, Belgium, Australia, Kenya, are trying to regulate the 
availability of information in the Internet for various reasons, none of them has been successful.

Perhaps the biggest problem for government censors is the sheer volume of content available on the Internet to oversee, particularly when the number of websites doubles every fifty-three days ("The Accidental Superhighway", 1995; Taubman, 1998). As illustrated earlier, the number of Chinese "netizens" is also increasing at a surprising rate. This fact makes it more and more difficult for the government to monitor users and observe whether they are visiting forbidden sites, and to check the e-mails. As one Chinese user pointed out,

If you really want to find stuff, then you will get through the wall ... and it is easy to get access through sites in northern Europe or Japan. Once you hit upon one, you just take a trip round the neighborhood through links they provide and you've got yourself a gold mine. (Barme \& Ye, 1997; Taubman, 1998)

\subsection{Conclusion}

The Right to Freedom of Opinion and Expression

Everyone has the right to freedom of opinion and expression; this right includes freedom to hold opinions without interference and to seek, receive and impart information and ideas through any media and regardless of frontiers.

Article 19. The Universal Declaration of Human Rights

The development of the Internet has been uneven in China. The original intention of the Internet as a medium form is to bring everyone everywhere unfiltered access to information. If this goal could be achieved by independent news agencies and dissident groups, the Internet would be a powerful channel for the government and ordinary Chinese to hear each other and to be heard. However, as illustrated in previous chapters, the Chinese government has been put into a dilemma on the development issue of the 
Internet since its introduction to China in late 1980s. On the one hand, the Chinese government wants to use the Internet to help promote economic growth; on the other hand, it tries to prevent its people from having unfettered use of the Internet and being fully embraced by various contents in the Internet. As previous chapters describe, the Chinese government issued related regulations on Internet administration and also controls the online content. Thus, the situation of the Internet in China turns out to be a struggle over "whether the government's control of all information flow in China can be successfully challenged by the Internet, or whether China will pioneer ways that defeat the Internet's original liberating promise along the way setting a precedent for a central government successfully controlling information and showing other repressive governments how to subdue this powerful technology" (Dong, 2002). In recent years, as investigated by Amnesty International, the controls placed on operators and users of the Internet have increased greatly and this has taken the form of censorship and penalties against all those involved with bulletin boards, chat rooms, e-mail and search engines who contravene the provisions of the Criminal Law and the scores of regulations (Amnesty International, 2002). This struggle will likely last until political reform finally comes to China.

But no matter what efforts governments make to control the Internet, the Internet develops in its own free way. Although from the very beginning, the Chinese government has been playing a crucial role in how the Internet develops, it aims to integrate China with the global market economy, which determines its open and active attitude toward the Internet. Once the government decided that the Internet could help the country benefit from the lucrative digital economy, it gave full support to the Internet's growth by 
formulating guiding policies and investing in the construction of a telecommunication infrastructure. But, the Chinese government is aware that the Internet is a double-edged sword, which brings both great opportunities and challenges. Thus, as a result, the Chinese government has tried to set boundaries for the Internet. The Chinese government's control on the Internet, both from a policy and technology standpoint, stems from a desire to assert political and social control. However, it is certain that the Internet will maintain its momentum of rapid development in China despite the restrictions imposed on it and will have an even greater influence on Chinese society. China is moving toward greater freedom, after all, since the introduction of the Internet. 
Note:

${ }^{1}$ These ten network operators are China Public Computer Network (CHINANET), China Science and Technology Network (CSTNET), China Education and Research Network (CERNET), China Golden Bridge Network (CHINAGBN), China Unicom Network (UNINET), China Net and Computer Network (CNCNET), China Mobile Network (CMNET), China International Economic and Trade Network (CIETNET), China Great Wall Network (CGWNET), and China Satellite Network (CSNET). Among them, CSTNET, CERNET, CIETNET and CGWNET are non-profit organizations. 


\section{Bibliography:}

1. Amnesty International Association. People's Republic of China: State control of the Internet in China. http:/www.web.amnesty.org/ai.nsf/recent/asal 70072002 , November 26, 2002

2. Bittner, R. John. Mass Communication. Massachusetts: Allyn and Bacon, 1996

3. Caimcross, Frances. The Death of Distance: How the Communications Revolution Is Changing Our Lives. Massachusetts: Harvard Business School Press, 2001

4. Cassata, B. Mary \& Asante, K. Molefi. Mass Communication: Principles and Practices. London: Collier Macmillan Publishers, 1979

5. Chartrand, Hillman Harry. "Intellectual Property Rights in the Postmodern World", Journal of Arts Management, Law \& Society. Vol. 25, Issue 4, Winter 1996 6. Chen, Guo-Ming \& Starosta, J. William. Communication and Global Society. New York: Peter Lang Publishing, 2000

7. China Education and Research Network. "Education Information Network," http://www.cdu.cn/ (In Chinese), 2002

8. China Internet Network Information Center. "Survey Report on China's Internet Development," http://www.cnnic.net/ (In Chinese), 2003

9. Davison, W. Phillips; Boylan, James \& Yu, T. C. Frederick. Mass Media: Systems and Effects. New York: CBS College Publish, 1982

10. Dong, Bill. Forbidden sites hijacked all over China. Washington, D.C.: Dynamic Internet Technology Inc., http://www.dit-inc.us/report/hj.htm, October 1, 2002 11. Einhorn, Bruce. "Is Your Web Site Available in China?", Business Week Online. http://www.businessweek.com/bwdaily/dnflash/sep2002/nf20020916_2066. hm 
September 16,2002

12. Gutstein, Donald. E.con: How the Internet Undermines Democracy. California: Stoddart, 1999

13. Huang, Edgar. "Flying Freely But In The Cagean Empirical Study of Using Internet For the Democratic Development in China", Information Technology for Development. Vol. 8, Issue 3, 1998

14. Jin, Ran. "Information Transmission on the Internet", Zijin.net. http:/www.zijin.nct/gb/content/2003-01/01/content 43.htm (In Chinese), January 1, 2003 ,

15. Kalathil, Shanthi \& Boas, C. Taylor. The Internet and state control in authoritarian regimes: China, Cuba, and the counterrevolution. Washington D.C.: Carnegie Endowment for International Peace, 2001

16. Kamarck, Ciulla Elaine \& Nye Jr., S. Joseph, ed. Governance.com: Democracy in the Information Age, Visions of Governance in the $21^{\text {st }}$ Century. Washington, D.C.: Brookings Institution Press, 2002

17. Kenway, Jane. "The Information Superhighway and Post-modernity: The Social Promise and the Social Price", Comparative Education. Vol. 32, Issue 2, June 1996 18. Kizza, Migga Joseph. Civilizing the Internet: Global Concerns and Efforts Toward Regulation. North Carolina: McFarland \& Company, Inc., 1998

19. Kneteman, Lindsay. "Changing the world with computers", Ryerson's Independent Student Newspaper. Volume 36, Issue 17, January 29, 2003

20. Lee, S. N. Paul. Telecommunications and Development in China. New Jersey: Hampton Press, INC., 1997 
21. Lorimer, Rowland. Mass Communications. Manchester: Manchester University Press, 1994

22. Margolis, Michael \& Resnick, David. Politics As Usual. London: Sage Publications, 2000

23. Mclntyre, T. Bryce. Mass Media in the Asian Pacific. Clevedon: Multilingual Matters Ltd, 1998

24. McQuail, Denis. Mass Communication Theory. London: Sage Publications, 1987

25. National Administration Institute. Internet Information Service Management Methods. http:/chinalawinfo.com/Frcclaw/ShowFramc.cgi (In Chinese), 2000

26. Nesbitt-Larking, Paul. Politics, society and the media: a Canadian perspective. Ontario: Broadview Press, Ltd., 2001

27. O'Neil, H. Patrick. Communicating Democracy: The Media and Political Transitions. Boulder: Lynne Rienner Publishers, Inc., 1998

28. Public Security Ministry. International Information Network Security Protection Management Methods. http//chinalawinfo.com/Freclaw/ShowFrame.cgi (In Chinese), 1997

29. Rogerson, S. Kenneth \& Thomas, G. Dale. "Internet Regulation Process Model: The Effect of Societies, Communities, and Governments", Political Communication. Vol. 15, Issue 4, October - December 1998

30. Shapiro, L. Andrew. The Control Revolution: How the Internet is Putting Individuals in Charge and Changing the World We Know. New York: PublicAffairs, 1999 
31. Stevenson, L. Robert. Global Communication In The Twenty-First Century. New York: Longman, 1994

32. Taubman, Geoffry. "A Not-So World Wide Web: the Internet, China and the Challenges to Nondemocratic Rule", Political Communication. Vol. 15, Issue 2, April June 1998

33. Tsui, Lokman. "Internet in China: Big Mama is Watching You", University of Leiden. http://www.lokman.nu/thesis/, 2001

34. Weaver, Rose Lisa. "China blocks AltaVista search engine", CNN.com. http:/edition.cnn.com/2002/TECH/internct/09/06/china.google/index.html, September 6, 2002

35. Xing, Fan. Communications and Information in China. Lanham: University Press of America, lnc., 2001

36. Zhou, Lu. "Firewall - The New 'Great Wall' of China", The University of Wisconsin - Madison. www.sit.wisc.edu/_LuZhou/, November 29, 2000 